\title{
Public engagement in cancer control in Canada
}

\author{
Michelle Cleghorn
}

University of Toronto

By informing the public about relevant and timely issues as well as facilitating public input in policy development, public engagement in cancer control - as with many areas of health care - can increase the fairness and legitimacy of decisions and policies made by public officials. Equally important, public engagement holds policy makers accountable to the wider public for their decisions that are supposed to serve the public's interests. In these ways it enhances accountability for reasonableness ${ }^{1}$. While the ultimate goal of public engagement in health care is to keep citizens' values, preferences and priorities reflected in what is essentially 'their' healthcare system ${ }^{2}$, engagement specifically in the area of cancer control fosters education on cancer prevention while simultaneously involving the public in processes of improving cancer care delivery ${ }^{3}$, research ${ }^{4}$ and policy ${ }^{5}$. One clear example where public engagement has impacted health care guidance, is regarding patient information and choice in screening technologies for the early detection of colorectal cancer in Ontario ${ }^{6}$.

Unfortunately, much of the literature published to date on public engagement relates to other domains of health care, and little is known about the Canadian public's values concerning cancer and its care, including those around different cancer interventions, outcomes from these interventions and how resources should be distributed among the population at need. In Canada, cancer affects approximately $45 \%$ of men and $39 \%$ of women, with about one in four individuals dying from the disease ${ }^{7}$. The recent paradigm shift in science and medicine towards personalized care, especially in regards to cancer treatment ${ }^{8}$, together with greater consumerism and patients wanting options around treatment $^{9}$ brings new economic concerns to the sustainability of cancer care, as well as ethical concerns associated with biobanking and treatment allocation. For example, many new pharmaceuticals and treatments are being developed for specific groups of patients and public funding limitations raise concerns about access to innovative and potentially beneficial treatments. Cancer drugs and biologics alone now occupy $30 \%$ of provincial cancer budgets, and "the annual growth rate of oncology drug sales is roughly double that of the overall pharmaceutical market."7 Recognizing that limited resources require hard choices to be made by authorities, public engagement could assist in the setting of difficult priorities $^{10}$ for cancer control $^{11}$, thereby helping to legitimize the deliberation or decision process utilized for making fiscal decisions.

In order to reduce the burden of cancer on the Canadian population, cancer must be controlled at the intersection of public health and health policy. From prevention, treatment and the pursuit of a cure for cancer to survivorship, public engagement can contribute to better policy development. Regarding cancer prevention, an effective public engagement process that is broad and transparent in nature would not only increase the likelihood of public opinion influencing policy making, but would also support education of the public at large, equipping citizens with appropriate information to improve their collective health. Since there is often a chronicity to cancer that arises from several co-morbid conditions, such as heart disease and chronic obstructive pulmonary disease, an ideal strategy may be to take lessons learned from a public health-chronic disease perspective and apply them to public engagement in cancer prevention and control as more literature is generally available on public involvement in chronic disease. Moreover, although cancer is unique in many of its causal pathways, several risk factors overlap with other diseases, opening up opportunities for transfer of education, policy and public opinion across conditions. For instance, the genetic components of cancer prompt 
important questions around newborn screening, adult predictive genetic testing ${ }^{12}$, etc., which comprise more general policy issues that span across medical conditions. Public engagement would also act to elicit consumer and patient preferences in terms of the diagnosis and treatment of cancer, identifying technologies ${ }^{13}$, interventions and resource allocation models considered useful and appropriate by the public. This engagement could be employed to make similar prioritizations in cancer research and to plan the direction of future research agendas. Finally, with the goal of improving life with and after cancer, survivors should be included as active participants in the public engagement process. With a wealth of first-hand knowledge and insight into the cancer experience within the Canadian healthcare system, they have a unique opportunity to advise on health services that would be more responsive to the needs of future cancer patients.

Policy makers want to involve citizens in the decisions that affect them ${ }^{14}$, but often do not know how to do so effectively. The positive trend in public engagement towards the use of deliberative methods (e.g. citizens councils, Deliberative Polling $\left.{ }^{\circledR}\right)$ and more dialogue with the public versus one-way elicitation of public views ${ }^{15}$, does not seem to be utilized in cancer control. If public engagement is primarily operating to improve the fairness and legitimacy of health care decision-making and policy, perhaps its effectiveness should be measured by the accountability for reasonableness framework ${ }^{1}$. Furthermore, public engagement could advance public health education efforts in addition to ensuring health services embody the values, preferences and expectations of both consumers and patients.

\section{Acknowledgments}

This commentary is related to preliminary work being completed in collaboration with Drs. Jennifer Gibson and Stuart Peacock as part of the Canadian Centre for Applied Research in Cancer Control's agenda (http://www.cc-arcc.ca/research/socval/).

\section{References}

1. Daniels N, Sabin JE. Setting limits fairly: learning to share resources for health $\left(2^{\text {nd }}\right.$ ed). New York: Oxford University Press; 2008.

2. McCabe C, Stafinski T, Menon D. Is it time to revisit orphan drug policies? BMJ 2010;341:c4777.

3. Attree P, Morris S, Payne S, Vaughan S, Hinder S. Exploring the influence of service user involvement on health and social care services for cancer. Health Expect 2011;14:48-58.
4. McCormick S, Brody J, Brown P, Polk R. Public involvement in breast cancer research: an analysis and model for future research. Int J Health Serv 2004;34:62546.

5. Paul C, Nicholls R, Priest P, McGee R. Making policy decisions about population screening for breast cancer: the role of citizens' deliberation. Health Policy 2008;85:31420.

6. Citizens panel contributes to assessment process for Ontario's health technologies, 27 October 2009 (http://www .chepa.org/News-Archives/09-1027/Citizens panel contributes to assessment process for Ontario s health technologies.aspx).

7. Vogel L. Pan-Canadian review of cancer drugs will not be binding on provinces. CMAJ 2010;182:887-8.

8. Curwin K, Paige CJ, Sutcliffe S. The Terry Fox Research Institute's Ontario Dialogue: how will personalized medicine change health care? Curr Oncol 2011;18(1):33-8.

9. Mileshkin L, Schofield PE, Jefford M, Agalianos E, Levine M, Herschtal A, Savulescu J, Thomson JA, Zalcberg JR. To tell or not to tell: the community wants to know about expensive anticancer drugs as a potential treatment option. J Clin Oncol 2009;27:5830-7.

10. Chafe R, Levinson W, Hébert PC. The need for public engagement in choosing health priorities. CMAJ 2011;183:165

11. Martin DK, Abelson J, Singer PA. Participation in health care priority-setting through the eyes of the participants. $J$ Health Serv Res Policy 2002;7:222-9.

12. Martin DK, Greenwood HL, Nisker J. Public perceptions of ethical issues regarding adult predictive genetic testing. Health Care Anal 2010;18:103-12.

13. Chafe R, Merali F, Laupacis A, Levinson W, Martin D. Does the public think it is reasonable to wait for more evidence before funding innovative health technologies? The case of PET scanning in Ontario. Int J Technol Assess Health Care 2010;26;192-7.

14. Scutchfield FD, Hall L, Ireson CL. The public and public health organizations: issues for community engagement in public health. Health Policy 2006;77:76-85.

15. Mitton C, Smith N, Peacock S, Evoy B, Abelson J. Public participation in health care priority setting: a scoping review. Health Policy 2009;91:219-28.

\section{Author Profile}

Recently, Michelle successfully defended her M.Sc. thesis at the Institute of Medical Science on public engagement in health policy under Dr. Ross Upshur's supervision. In her program, she also completed the Collaborative Program in Bioethics at the Joint Centre for Bioethics. She is currently working with Drs. Jennifer Gibson and Stuart Peacock at the Canadian Centre for Applied Research in Cancer Control on 'Setting research priorities for public engagement in cancer control: A national workshop' through a CIHR MPD grant. 